\title{
DOS CANTOS AL CENTENARIO \\ EN EL MARCO HISTORICO-SOCIAL DEL MODERNISMO EN LA ARGENTINA
}

\author{
POR \\ MIREYA CAMURATI \\ State University of New York at Buffalo
}

Los estudios generales sobre el modernismo coinciden en reconocer el lugar destacado que ocupó la Argentina en el desarrollo del movimiento. Algunos especialistas en el tema anotan afirmaciones rotundas: «En la historia del modernismo hispanoamericano hubo un hombre y una ciudad importante: el hombre fue Rubén Darío; la ciudad fue Buenos Aires» ${ }^{1}$. Esta opinión resulta extrema, excepto si la referencia se limita a los últimos años del siglo XIX, que incluyen la presencia de Darío en la capital argentina, donde, en 1896, el nicaragüense publica Prosas profanas y Los raros. Por otra parte, también es cierto que, desde muy temprano, Buenos Aires fue centro de divulgación de ideas y publicaciones modernistas. Como ejemplo elocuente baste recordar que José Martí enviará colaboraciones a La Nación desde 1882 hasta 1891 y que, como es bien sabido, el prestigioso diario porteño no sólo acogió y difundió en sus páginas los escritos de Darío, sino que también, en varias ocasiones, fue la única fuente de recursos con la que pudo contar el pobre poeta.

Si se fija la atención en los modernistas argentinos, lo primero que se advierte es la figura monumental de Leopoldo Lugones. En la prosa, sólo Enrique Larreta podrá equiparársele. En la lírica, Leopoldo Díaz, Angel de Estrada, Alberto Ghiraldo, Carlos Ortiz, Eugenio Díaz Romero o Carlos Guido y Spano, en cuanto se considere a este último como precursor del modernismo ${ }^{2}$, deben figurar a mucha distancia del poeta cordobés.

${ }^{1}$ Carlos Alberto Loprete, La literatura modernista en la Argentina (Buenos Aires: Poseidón, 1955), p. 9.

${ }^{2}$ Consultar el libro de Carlos Alberto Loprete Carlos Guido y Spano (Buenos Aires: Ediciones Culturales Argentinas, 1962), y el artículo de Alfredo A. Roggiano «Guido Spano y el modernismo hispanoamericano», en Boletín del Instituto de Investigaciones Literarias, 6, Facultad de Humanidades y Ciencias de la Educación, Universidad Nacional de La Plata, Argentina (1951): 93-121. 
E1 panorama del modernismo en la Argentina es extenso y complejo $\mathrm{y}$, como tal, puede estudiarse desde distintas perspectivas. La que adoptamos en estas páginas es aquella que hace convergir, en determinado momento y circunstancias, varias coordenadas significativas. La fecha elegida es 1910, año en que la Argentina festeja el centenario de la revolución de independencia. En el número especial en conmemoración del 25 de mayo, La Nación publica el Canto a la Argentina, de Rubén Dario, y «A los ganados y a las mieses», el poema más extenso de los que integran las Odas seculares, de Leopoldo Lugones.

La época es de regocijo, y el país celebra no sólo las glorias pasadas, sino la prosperidad y enorme desarrollo del presente. Si bien luego se calificarán a estos sentimientos y actitudes como las «ilusiones del centenario» ${ }^{3}$, en la superficie la imagen es positiva:

Aunque como país periférico y dependiente, la Argentina crecía. Aumentaban las cifras de sus exportaciones agropecuarias, así como la extensión de sus vías férreas; se secularizaban las instituciones de la sociedad civil, y el capital extranjero, después de la crisis de 1890, volvía a mostrarse confiado en el orden de la república oligárquica ${ }^{4}$.

Desde el punto de vista de la economía política, son los años en los que se afianza en Latinoamérica lo que Tulio Halperin Donghi denomina el «nuevo pacto colonial», que básicamente consiste en designar a Iberoamérica como proveedora de materias primas y productos agropecuarios para las metrópolis industriales europeas y norteamericanas, y como consumidora de los productos manufacturados que aquéllas exportan. Este pacto se afirma aún más con la política del librecambio ${ }^{5}$. En un estudio en el que aplica estrictamente la teoría marxista, Françoise Perus observa que el modernismo, como período que va de 1880 a 1910 , corresponde en América Latina a «la implantación del modo de producción capitalista en escala continental» ${ }^{6}$. En realidad, este último juicio identifica una evidencia reconocida por la crítica actual, cualquiera sea su ideología. Así, Gutiérrez Girardot considera oportuno estudiar al modernismo dentro del «contexto histórico general de la expansión del capitalismo y de la socie-

${ }^{3}$ Julio Irazusta, Balance de siglo y medio (Buenos Aires: Theoria, 1966), capítulo IX.

${ }^{4}$ Carlos Altamirano y Beatriz Sarlo, «La Argentina del Centenario: Campo intelectual, vida literaria y temas ideológicos», en Hispamérica, 9.25-26 (1980): 37.

${ }_{5}^{5}$ Tulio Halperin Donghi, Historia contemporánea de América Latina (Madrid: Alianza, 1969), pp. 214-215.

- Françoise Perus, Literatura y sociedad en América Latina: El modernismo (México: Siglo Veintiuno, 1976), p. 43. 
dad burguesa», contexto que incluye una «compleja red de 'dependencias' entre los centros metropolitanos, sus regiones provinciales y los países llamados periféricos» ${ }^{7}$. Y Angel Rama, en un trabajo esclarecedor ${ }^{8}$, no sólo parte de este supuesto, sino que lo desarrolla en las derivaciones que explican algunas de las características y principios estéticos del escritor modernista. Por ejemplo, relaciona la exaltación del subjetivismo en arte (Darío: «Mi poesía es mía en mí»; "Sé tú mismo: ésa es la regla») con la norma de la economía liberal. Dice:

La subjetivación refuerza el criterio de la desemejanza de los hombres, abre el camino hacia la originalidad como principio -o como incentivo- de la creación, y aspira a que ella, funcionando como verdadera «patente de fabricación», sea preservada de toda imitación, resulte irrepetible en el mercado ${ }^{9}$.

También Rama interpreta la actitud de asumir la poesía como especialización, actitud que en su postura más extrema proclama el principio del Arte por el Arte como un efecto de la división del trabajo que introduce la nueva economía capitalista ${ }^{10}$.

En la misma línea, el crítico uruguayo entiende el rechazo del burgués materialista, posición en la que coincidieron todos los escritores modernistas, como una respuesta antagónica a quien había instaurado un mercado en el que el artista va a ser considerado como productor de mercancías, sometido a las leyes de la competencia y forzado a presentar su obra a una masa anónima de consumidores: el público ${ }^{11}$.

En las páginas de su ensayo, Rama dilucida estos y otros temas de la estética modernista, como el antiacademicismo, aristocratismo y cosmopolitismo, siempre sobre la base y en correspondencia con los factores socioeconómicos.

Especialmente pertinentes para nuestro tema son las reflexiones que el crítico desarrolla sobre el periodismo. Ve a éste como «parte de la empresa histórica de la burguesía», la que tiene en los diarios su «instrumento de acción intelectual» ${ }^{12}$. Si volvemos ahora a La Nación, hay que recordar que este periódico fue fundado en enero de 1870 por Bartolomé

${ }^{7}$ Rafael Gutiérrez Girardot, Modernismo (Barcelona: Montesinos, 1983), p. 25.

\& Angel Rama, Rubén Darío y el modernismo (Circunstancia socioeconómica de un arte americano) (Caracas: Ediciones de la Biblioteca de la Universidad Central de Venezuela, 1970).

9 Rama, p. 16.

${ }^{10}$ Rama, pp. 44-48.

11 Rama, pp. 49-50.

12 Rama, p. 68. 
Mitre, presidente de la República entre 1862 y 1868 , jefe militar en la guerra del Paraguay, campeón de la causa porteña en las luchas entre Buenos Aires y la Confederación, historiador y traductor de Dante y Horacio. A principios de 1895, Darío publica en La Nación un artículo titulado «La vida literaria: A propósito de los dos últimos libros del general Mitre» ${ }^{13}$. El texto interesa no sólo por la evaluación de los trabajos horacianos de Mitre, sino especialmente porque incluye la transcripción de una carta de Luis Berisso, aliado de Darío en el movimiento renovador y, como él, colaborador del diario. Berisso lamenta la posición rebajada que ocupa el escritor en la sociedad de la época: «Por desgracia, entre nosotros, el pensador, el literato, el artista, no tiene escena propicia: lo mata la indiferencia pública y el ambiente burgués» ${ }^{14}$. Berisso continúa sus quejas contra el gusto «encanallado», contra el dinero que se gasta en orgías, carreras, juegos, o en «todos los refinamientos del bizantinismo avasallador y triunfante», y que, en cambio, no se utiliza para comprar un libro. Por esto alaba la vocación del general Mitre, quien, ya en la vejez, sigue brindándose a las labores literarias.

A la muerte de Mitre, en 1906, Darío le dedicará una oda, en la que exalta sus acciones de estadista y militar, junto con las predilectas tareas del espíritu:

Y para mí, Maestro, tu vasta gloria es ésa:

amar los hechos fugaces de la hora, sobre la ciencia a ciegas, sobre la historia espesa, la eterna Poesía, más clara que la aurora ${ }^{15}$.

Según leemos en su Autobiografía, Darío siempre manifestó gran estima por el diario porteño: «Yo tenía, desde hacía mucho tiempo, como una viva aspiración el ser corresponsal de La Nación, de Buenos Aires» ${ }^{16}$. Por otra parte, sabemos que esta actitud no era privativa del nicaragüense. En comentarios sobre el ambiente intelectual del Centenario se mencionan «las relaciones de protección paternal y devoción filial que los escritores mantienen con La Nación» ${ }^{17}$. Este sistema se apoya en la alta calidad intelectual de los directores y redactores del periódico. Cuando, recién

${ }^{13}$ Rubén Darío, Obras completas, IV (Madrid: Afrodisio Aguado, 1955), pp. 745766.

${ }^{14}$ Darío, Obras completas, IV, p. 750.

15 Rubén Darío, Obras poéticas completas (Madrid: Aguilar, 1941), p. 745. De aquí en adelante, las referencias a los poemas de Darío se harán sólo por número de página, según esta edición.

${ }_{16}$ Rubén Darío, Obras completas, I (Madrid: Afrodisio Aguado, 1950), p. 60.

${ }^{17}$ Altamirano y Sarlo, p. 40. 
llegado al país, Darío se presenta a La Nación, el administrador del diario era Enrique de Vedia; el secretario de redacción, Julio Piquet, y entre los colaboradores figuraban Roberto J. Payró y José Miró, el «Julián Martel» autor de La Bolsa. Con emoción y respeto, Darío recuerda el primer encuentro con Bartolomé Mitre, «aquel varón de historia y de gloria»:

Me habló el general Mitre de Centroamérica y de sus historiadores Montúfar, Ayón, Fernández; recordó al poeta guatemalteco Batres, autor de El Reloj; habló de otras cosas más. Me hizo algunas preguntas sobre el canal de Nicaragua. Estuvo suave y alentador en su manera seria y como triste, cual de hombre que se sabía ya dueño de la posteridad ${ }^{18}$.

Si de esta imagen enaltecida pasamos a la que surge de un análisis histórico o sociológico, la diferencia es apreciable. En esta última, Mitre aparece entre «los detentadores de la ciudad-puerto Argentina, que desarrolla y a la vez somete al país a la órbita de los imperios europeos» ${ }^{19}$. $Y$ se agrega que ese proceso pudo cumplirse

con mayor comodidad y alcance a partir del aniquilamiento de las resistencias provincianas, del ingreso de la inmigración extranjera, y debido al tipo especial de producción - agricultura y ganadería - que se adecuó a las necesidades de complementación económica de las metrópolis industrializadas ${ }^{20}$.

Aquí tenemos un ejemplo evidente de las discrepancias entre dos visiones de un personaje o de determinadas circunstancias, visiones que en sí mismas intentan ser verídicas y ajustadas a la realidad que reflejan. Darío nos da la suya desde un punto de vista subjetivo, en el recuerdo emocionado de la figura patricia del general Mitre, y con el énfasis en las virtudes de éste como hombre de letras, conocedor de autores menores de su tierra centroamericana. Rama y las fuentes de investigación histórica y sociológica en las que se apoya presentan a Mitre como uno de los agentes de la implantación del neocolonialismo en Hispanoamérica. Disparidades de este tipo deben tenerse en cuenta al tiempo de emitir juicios de valor sobre el historiador, el crítico o el literato.

Siempre en el análisis de las circunstancias histórico-sociales que respaldan el tono y los temas de los cantos al Centenario, conviene precisar ahora las referencias a la ubicación de la Argentina en cuanto a su inser-

\footnotetext{
${ }^{18}$ Darío, Obras completas, I, p. 110.

19 Rama, p. 31.

${ }^{20}$ Rama, p. 32.
} 
ción en el sistema económico internacional. El nuevo pacto colonial al que se refiere Halperin Donghi, y que madura alrededor de 1880, básicamente implica, en el caso de la Argentina, el desarrollo preponderante de la producción agropecuaria condicionada a los intereses de Inglaterra como metrópoli hegemónica. La influencia británica operó en Argentina desde la época de la independencia, cuando ya se apoya «en su predominio comercial, en su poder naval, en tratados internacionales» ${ }^{21}$. Paulatinamente, el poderío se afirmará con el monopolio que ejerce Gran Bretaña en la expansión de la red ferroviaria y con su dominio de los mercados financieros. Al respecto, comenta Halperin:

Los bancos ingleses, que desde la década del 60 se van instalando en América Latina, son los intermediarios casi exclusivos en el intercambio de metálico con Europa; la mayor parte de los gobiernos latinoamericanos usan a banqueros de Londres como sus principales agentes financieros ${ }^{22}$.

Sobre este punto es bueno recordar que Manuel Quintana, presidente de la Argentina desde 1904 hasta su muerte en 1906, había sido abogado del Banco de Londres y América del Sur y también de empresas ferroviarias inglesas ${ }^{23}$.

Los críticos destacan la habilidad británica en cuanto a ejercer su hegemonía manteniéndola en el plano de los intereses económicos y, con pocas excepciones, sin lanzarse en la búsqueda de un dominio político directo.

Desde principios de siglo, el panorama socioeconómico de la Argentina se hace más complejo, con la importancia creciente de una burguesía industrial, en muchos aspectos antagónica a la oligarquía terrateniente tradicional. Como vimos, esta última, exportadora de productos agropecuarios, se mantenía adherida a la órbita británica y a la práctica del librecambio. En posición opuesta, los representantes de las industrias nacionales solicitaban medidas proteccionistas y se inclinaban a integrarse en el área de la tecnología norteamericana. Veremos que, en determinado momento, Leopoldo Lugones será vocero de estas inquietudes y tendencias.

${ }^{21}$ Halperin Donghi, p. 154.

22 Halperin Donghi, pp. 224-225. Sobre el tema general de la influencia de Gran Bretaña en la vida económica y política de Argentina resultan de lectura provechosa los capítulos 3, 4 y 5 del libro de Halperin. Para un anáisis desde el punto de vista del nacionalismo revisionista puede consultarse el libro ya mencionado de Juio Irazusta Balance de siglo y medio.

${ }_{23}$ Alfredo Canedo, Aspectos del pensamiento político de Leopoldo Lugones (Buenos Aires: Ediciones Marcos, 1974), p. 89. 
Entre julio y agosto de ese año de 1910 , que ahora nos ocupa, se realizó en Buenos Aires la Cuarta Conferencia Interamericana. En muchos sentidos, los observadores la consideran la más feliz de las que esa organización internacional había realizado hasta la fecha, y suponen que a esto contribuyó en gran parte el clima de festejos y prosperidad que imperaba en la Argentina del Centenario ${ }^{24}$. En cuanto a la participación de los delegados argentinos en las deliberaciones, ésta fue mucho menos agresiva contra los Estados Unidos que la que cumplieron en la Primera Conferencia, realizada en Washington en 1889-1890, Manuel Quintana y Roque Sáenz Peña. Como se sabe, este último extendió allí los alcances del lema que sintetizaba la doctrina Monroe de "América para los americanos» con el de «América para la humanidad». La actitud argentina en estos foros internacionales evidenciaba, por un lado, el afán de liderar a las repúblicas hispanoamericanas, el recelo frente al poderío y a las tendencias expansionistas de los Estados Unidos, pero también una fuerte y a veces complacida relación de dependencia con el Imperio británico. En la lucha competitiva, que por la obtención de mercados y zonas de influencia se plantea entre Gran Bretaña y los Estados Unidos, la Argentina conservadora con frecuencia se desubica en el intento de mantenerse fiel a la metrópoli inglesa. Con la apertura generosa implícita en la fórmula de Sáenz Peña, Argentina podía preservar sus relaciones tradicionales con las potencias europeas.

Hasta aquí estos comentarios sobre las circunstancias históricas y sociales en las que se ubican los cantos del Centenario. Aunque incompletos en detalles y necesariamente limitados, ellos pueden favorecer una interpretación más ponderada de las cualidades de los autores y de las obras.

\section{Rubén Darío y el «CANTo a la Argentina»}

Darío escribió el Canto a la Argentina en París. Su amigo y biógrafo, Francisco Contreras, anota estos recuerdos:

Ciertos días, en que estaba tranquilo, me mostraba sus poemas nuevos y aun sus artículos. Una noche que lo encontré recogido, me leyó, en cama, vibrante aún del placer de la creación, su Canto a la Argentina, cuyo último verso acababa de escribir. «Imitarán esto también»,

${ }^{24}$ Samuel Guy Inman, Inter-American Conferences 1826-1954: History and Problems (Washington, D.C.: U. P. of Washington, D.C. and Community College P., 1965), p. 76. 
me dijo algo azorado. «Sin duda», le contesté riendo, y no me equivocaba ${ }^{25}$.

Contreras da una imagen desoladora del Darío de esta época. El poeta vive recluido, agobiado por penurias económicas, neurasténico y con frecuentes crisis de alcoholismo. El abatimiento espiritual que acompaña a la declinación física venía insinuándose en sus escritos desde hacía un tiempo. Por ejemplo, puede observarse en el tono y las reflexiones de "Marinetti y el futurismo», artículo que aparece en La Nación, de Buenos Aires, el 5 de abril de 1909. En él, Darío comenta «Fundación y manifiesto del futurismo», texto que F. T. Marinetti había publicado en París en febrero de ese año, y que constituye la primera proclama de la vanguardia poética europea. Aquí tenemos la circunstancia extraordinaria de que Rubén Darío, entonces la voz más alta de la lírica hispánica, se enfrenta con un escrito que exalta la audacia y la renovación en arte en una forma exageradamente declamatoria y violenta, pero con intenciones no tan distantes de aquéllas que lo habían animado en la lucha contra el academicismo y la retórica anquilosada. Su respuesta es reticente y cargada de melancolía. Dice: "Ah maravillosa juventud: Yo siento cierta nostalgia de primavera impulsiva al considerar que sería de los devorados, puesto que tengo más de cuarenta años» ${ }^{26}$. Y concluye el artículo con un párrafo de casi resignado fatalismo: «Lo Futuro es el incesante turno de la Vida y de la Muerte. Es lo pasado al revés. Hay que aprovechar las energías en el instante, unidos como estamos en el proceso de la universal existencia. $\mathrm{Y}$ después dormiremos tranquilos y por siempre jamás. Amén» ${ }^{27}$. Pero si éste era el tono y el ánimo del poeta por esos años, el Canto a la Argentina lo muestra, en cambio, lleno de entusiasmo.

Si bien se trata de una obra de encargo - La Nación se la había solicitado para el número del Centenario-, la emoción y el interés son auténticos. Darío quería a la Argentina. La prueba más evidente la hallamos en la dedicatoria de Cantos de vida y esperanza: «A Nicaragua, a la República Argentina.» Las dos patrias, una nativa, la otra adoptada. En el poema «Retorno», escrito con ocasión de su visita de regreso a Nicaragua en 1907, dice el poeta:

${ }^{25}$ Francisco Contreras, Rubén Dario. Su vida y su obra (Santiago de Chile: Ercilla, 1937), p. 136.

${ }^{26}$ Dario, Obras completas, I, p. 622.

${ }^{27}$ Darío, Obras completas, I, p. 623. Para un análisis más completo de este tema puede consultarse nuestro estudio Poesía y poética de Vicente Huidobro (Buenos Aires: Fernando García Cambeiro, 1980), pp. 34-64. 
Si pequeña es la Patria, uno grande la sueña.

Mis ilusiones, y mis deseos, y mis

esperanzas, me dicen que no hay patria pequeña.

Y León es hoy a mí como Roma a París (p. 756).

$\mathrm{Su}$ afecto por la tierra nicaragüense y, en general, centroamericana es indudable. También claro es el conocimiento de su gente y la preoctupación por su destino. El tan zarandeado tema de la posición política de Darío en cuanto a las relaciones de Hispanoamérica con los Estados Unidos se puede apreciar con mayor provecho si al comentario de los poemas más conocidos («Los cisnes», «A Roosevelt», «Salutación al águila») se agrega el de varios textos en prosa. No sólo nos referimos a «El triunfo de Calibán», ya bien divulgado, sino a otros, extensos y bien documentados, como «John Bull for Ever!» o «El fin de Nicaragua». En el primero ${ }^{28}$, Darío historia los intentos de usurpación territorial cumplidos por Inglaterra en el oeste de su país, en Bluefields y la costa de Mosquitos. El tono se hace a veces amargamente sarcástico, como cuando menciona una de las tramoyas de los británicos, que consiste en "coronar» a un rey de la tribu de los Mosquitos, quien, por supuesto, les servirá como personero para adelantar los intereses del Imperio. Refiere una conversación en Londres en la que lord Palmerston le explica al embajador norteamericano que el indígena «era tan rey como usted o como yo». Lo que más le duele a Darío es no sólo la aquiescencia y a veces cooperación del gobierno norteamericano en estos atropellos, sino la forma parcial y tendenciosa en la que periódicos importantes de los Estados Unidos se refieren a los hechos ocurridos.

También rico en la relación de sucesos que a veces suenan curiosamente actuales es «El fin de Nicaragua» ${ }^{29}$, artículo aparecido en La Nación de Buenos Aires el 28 de septiembre de 1912.

El momento es el de la invasión norteamericana a Nicaragua, y Darío comienza por referirse a una invasión anterior, la del filibustero William Walker. Cuenta que, siendo niño, pudo escuchar las coplas populares que se cantaban sobre éste. $\mathrm{Y}$ anota con ironía:

En tiempo de Walker era el tránsito por Nicaragua de aventureros. que iban a California con la fiebre del oro. $Y$ con unos vaporcitos en el Gran Lago, o lago de Granada, comenzó la base de su fortuna el

${ }^{28}$ Darío, Obras completas, IV, pp. 517-530.

${ }^{29}$ Rubén Dario, Escritos dispersos de Rubén Dario, I (Recogidos de periódicos de Buenos Aires) (La Plata, Argentina: Universidad Nacional de La Plata, Facultad de Humanidades y Ciencias de la Educación, 1968), pp. 261-264. 
abuelo Vanberbilt, tronco de tanto archimillonario que hoy lleva su nombre.

Habla del terror que impone el yanqui cuando sus tiradores «cazaban nicaragüenses como quien caza venados o conejos». Y resume el final de la empresa:

Y llegó Walker a imperar en Granada, y tuvo partidarios nicaragüenses, y hasta algún cura le celebró en un sermón, con citas bíblicas y todo, en la parroquia. Pero el resto de Centro América acudió en ayuda de Nicaragua, y con apoyo de todos, y muy especialmente de Costa Rica, concluyó la guerra nacional echando fuera al intruso.

De aquí pasa a analizar la situación de ese momento, en la que ve repetirse errores y bajezas semejantes. En esa misma ciudad de Granada «se formó una agrupación yanquista, que envió a Washington actas en que se pedía la anexión». Desde «New Orleans y New York iban los fondos para sustentar la revuelta». Habla de «dos yanquis que fueron tomados en momentos en que ponían minas para hacer volar dos barcos llenos de soldados del gobierno». Y con amarga sorna escribe: «De los barcos de guerra anclados en los puertos de Corinto y de Bluefields desembarcaron tropas para imponer el orden, para 'proteger las legaciones', como si se tratase de contener hordas chinas.»

El escritor ve la situación con recelo y pesimismo. Teme por la soberanía de su patria, temor que se probará justificado con la ocupación de Nicaragua hasta 1933.

Si Darío era un buen observador de los sucesos de la política internacional, también lo era de la local y de sus paisanos. Criado en una familia liberal de León, recuerda haber escuchado cuando niño los comentarios y las discusiones de los partidarios de la Unión de Centroamérica. Protegido en su adolescencia y juventud por muchos de los dirigentes de esas repúblicas, la gratitud hacia algún personaje lo hace a veces cauteloso en sus juicios. Así, cuando habla del presidente de El Salvador, el doctor Rafael Zaldivar, «hombre culto, hábil, tiránico para unos, bienhechor para otros, y a quien, habiendo sido mi benefactor y no siendo yo juez de historia en este mundo, no debo sino alabanzas y agradecimientos» ${ }^{30}$.

Pero en la mayoría de los casos es verídico y perspicaz para advertir los males de la política criolla. Por ejemplo, anota en su Autobiografia:

Durante su presidencia, Zelaya hizo progresar el país, no hay duda alguna. Se rodeó de hombres inteligentes, pero que, como sucede en

${ }^{30}$ Darío, Obras completas, I, p. 45. 
muchas partes de nuestro continente, hacían demasiada política y muy poca administración... ${ }^{31}$

Vemos que en la obra en prosa de Darío abundan los comentarios sobre temas sociales y políticos. El poeta vivió atento a los sucesos de su época, y aunque no con un compromiso total y una vocación de ofrenda personal como la que animaba a Martí, o un designio de participación cívica e ideológica como se observa en Lugones, su posición no es de ignorancia o de consentimiento hacia los males que aquejaban al continente $y$, en especial, a su pequeña Patria.

Antes de pasar al comentario del Canto a la Argentina nos permitiremos una última digresión, la que, por otro lado, resulta pertinente para este trabajo. Se trata de aportar algunos datos sobre las circunstancias en que apareció y fue escrita la «Salutación al águila». El tema de esta poesía, y su relación con la oda «A Roosevelt», ha sido analizado en forma apropiada por Pedro Salinas y Enrique Anderson Imbert ${ }^{32}$, entre otros. Todos los críticos mencionan que, como secretario de la legación nicaragüense, Darío había asistido a la Tercera Conferencia Interamericana, celebrada en Río de Janeiro, la que inició sus deliberaciones el 25 de julio de 1906. Parece que durante su permanencia en Río el poeta se enfermó y decidió entonces realizar una breve visita a Buenos Aires, adonde llegó el 19 de agosto. El 24 de ese mes, Darío partió de regreso a Europa, y al día siguiente, 25 de agosto, La Nación publicó la «Salutación al águila»:

En la «Epístola» a la señora de Leopoldo Lugones, Darío se refiere a su experiencia diplomática en Brasil:

Yo pan-americanicé

con un vago temor y con muy poca fe

en la tierra de los diamantes y. la dicha

tropical... (p. 669).

a pesar de Nabuco, embajador, y de

los delegados panamericanos que

hicieron lo posible por hacer cosas buenas (p. 669).

En fin, convaleciente, 1legué a nuestra ciudad

de Buenos Aires, no sin haber escuchado

a míster Root a bordo del Charleston sagrado (p. 670).

${ }^{31}$ Darío, Obras completas, I, pp. 167-168.

${ }^{32}$ Pedro Salinas, La poesía de Rubén Dario, 2." ed. (Buenos Aires: Losada, 1957); Enrique Anderson Imbert, La originalidad de Rubén Dario (Buenos Aires: Centro Editor de América Latina, 1967). 
Aunque en estos versos Darío habla con displicencia de todo el episodio, sus biógrafos recuerdan que el poeta «tenía una ilusión infantil por las cosas de la diplomacia» ${ }^{33}$.

Ciertamente, el esplendor de las ceremonias y los discursos en la Conferencia de Río de Janeiro fue como para impresionar aun a aquellos menos sensibles que el poeta. Como sede para las sesiones, el gobierno brasileño reconstruyó en Río el edificio que había erigido en la Feria Mundial de St. Louis en 1903, y le dio el nombre de Palacio Monroe ${ }^{34}$. Entre sus representantes sobresalían el ministro de Relaciones Exteriores, Barón de Río Branco, y el embajador en Washington, Joaquim Nabuco, a quien Darío menciona en sus versos. Pero quien realmente marcó el punto culminante de la oratoria del Congreso fue el secretario de Estado norteamericano, Elihu Root. Hábil político de Nueva York, Root estaba mucho mejor informado que la mayoría de sus compatriotas acerca de los asuntos latinoamericanos, y también parecía sinceramente interesado en establecer mejores relaciones con los pueblos al sur del Río Grande. Root no sólo convence al presidente Roosevelt para que lo envíe al Congreso de Río de Janeiro, sino que, además, organiza una gira continental, en la que visitará varios países de la América del Sur.

En esos momentos era evidente que los Estados Unidos debían contar con sus mejores voceros para hacer frente a la ola de críticas provocada por las intervenciones norteamericanas en Centro América y el Caribe.

El 31 de julio de 1906 se realiza en Río de Janeiro una sesión extraordinaria de la Conferencia, en la que va a hablar Elihu Root. La expectativa es grande, y el discurso del secretario de Estado va a impresionar a su auditorio. Las primeras palabras parecen ser una respuesta directa en reconocimiento de lo que Darío alegaba en la oda "A Roosevelt». Dice Root: «En nombre de mi país traigo un saludo especial para nuestras hermanas mayores en la civilización de América» ${ }^{35}$.

En su oda, Darío había exaltado

la América nuestra, que tenía poetas

desde los viejos tiempos de Netzahualcoyotl, que ha guardado las huellas de los pies del gran Baco, que el alfabeto pánico en un tiempo aprendió;

la América del grande Moctezuma, del inca (p. 564).

${ }^{33}$ Contreras, p. 120.

${ }^{34}$ Inman, p. 66.

${ }_{35}$ «I bring from my country a special greeting to her elder sisters in the civilization of America», en Elihu Root, Speeches. Incident to the Visit of Secretary Root to South America. July 4 to September 30, 1906 (Washington D. C.: Government Printing Office, 1906), p. 7. 
Root llega al momento principal de su discurso, cuando afirma:

Consideramos que la independencia del miembro más pequeño y más débil de la familia de las naciones tiene derecho a gozar de iguales prerrogativas y a exigir igual respeto que la del más poderoso imperio, y consideramos la observancia de ese respeto como la garantía principal del débil contra la opresión del fuerte. No reclamamos ni deseamos ma. yores derechos, privilegios o poderes que los que libremente concedemos también a todas y a cada una de las repúblicas americanas ${ }^{36}$.

Aunque posteriormente se acuse en esta política norteamericana la falacia de proponer que se trataba de «una comunidad de naciones libres e iguales» ${ }^{37}$, en esa ocasión las palabras del secretario de Estado van a resonar gratamente en los oídos de muchos de los delegados, quienes deseaban escuchar algo que tranquilizara su recelo hacia el poder $\mathrm{y}$, frecuentemente, la prepotencia de los Estados Unidos.

A bordo del crucero «Charleston», Root va de Río de Janeiro a Montevideo y, en seguida, a Buenos Aires. Allí participa en numerosos actos y contesta, entre otros, a discursos del presidente José Figueroa Alcorta y de Luis María Drago, quien, en los foros internacionales, venía sustentando la que quedará como la doctrina de su nombre, y que determina que el cobro de la deuda pública de un país no es justificación para la intervención armada de otro. Por esos mismos días, Darío estaba en la capital argentina y habrá podido confirmar entonces ciertas impresiones e ideas recogidas en Río de Janeiro, y que se manifiestan no sólo en la «Salutación al águila», sino también en otros de sus textos. Una de ellas, fundamental para el tema que nos ocupa, es la de ver a la Argentina como la abanderada de las naciones hispanoamericanas y quizá la única que podía equilibrar de alguna manera el peso de la gran República del norte. Frente a la multiplicidad de las estrellas en el cielo y el pabellón norteamericano, dice en la oda «A Roosevelt»: «(Apenas brilla, alzándose, el argentino sol / y la estrella chilena se levanta...)» (p. 564). En la «Salutación al águila» advierte: «Aguila, existe el Cóndor. Es tu hermano en las grandes alturas. / Los Andes le conocen y saben que, cual tú, mira al Sol» (p. 642). $\mathrm{Y}$ en el poema en prosa «A la Argentina», que, aunque mucho más breve, en sus temas básicos resulta paralelo al Canto, expresa claramente: «Has podido oponer al águila yanqui el cóndor» ${ }^{38}$.

${ }^{36}$ James Brown Scott, La política exterior de los Estados Unidos (Nueva York: Doubleday, Page and Company, 1927, p. 78.

${ }^{37}$ Halperin Donghi, p. 292.

${ }^{38}$ Darío, Obras completas, IV, p. 451. 
Centrándonos, por fin, en el Canto a la Argentina, y en ese año de 1910 en que lo redacta, podemos ahora calcular mejor el estado de ánimo $\mathrm{y}$ las intenciones del poeta.

El hecho de que se trate de una obra que se le había encargado para determinada fecha, cuenta como explicación de elementos forzados en la estructura o de la calidad desigual de algunos de los versos. Para ayudarse, Darío recurre a su oficio poético. Va a las fuentes clásicas - Horacio, Ovidio, la Biblia ${ }^{39}$ - o trae reminiscencias del Santos Vega de Rafael Obligado. Dice Darío:

Os espera el reino oloroso

al trébol que pisa el ganado (p. 764).

En la tercera sección de su poema, titulada «E1 himno del payador», Obligado presenta al gaucho cantor cuando arenga a su auditorio para que se una en las luchas por la libertad. En caso de fracasar en ese intento de emancipación, pide para sí la condena:
si jamás independiente
veo el suelo en que he cantado, no me entierren en sagrado donde una cruz me recuerde: entiérrenme en campo verde, donde me pise el ganado! 40

En «El himno del payador» se convoca la memoria del 25 de mayo de 1810, cuando Buenos Aires lideró el movimiento revolucionario, y en la última estrofa se recuerdan las hazañas de los que siguieron a Belgrano, Güemes y a aquellos que, con San Martín, «se lanzaron / tras el Andes colosal» ${ }^{41}$. Darío alude a estos hechos en varias estrofas de versos vibrantes:

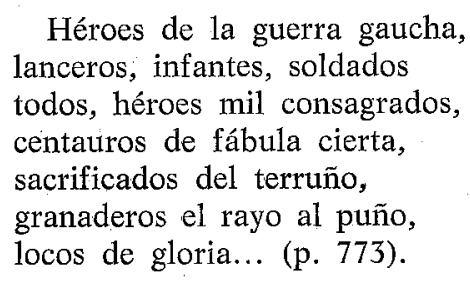

\footnotetext{
${ }^{39}$ Para este tema, consúltese el estudio de Arturo Marasso Rubén Dario y su creación poética (Buenos Aires: Biblioteca Nueva, 1941), pp. 328-333.

${ }^{40}$ Rafael Obligado, Santos Vega y otras leyendas argentinas (Buenos Aires: Kapelusz, 1955), p. 29.

${ }^{41}$ Obligado, p. 30.
} 
También recuerda a San Martín en su callada vejez:

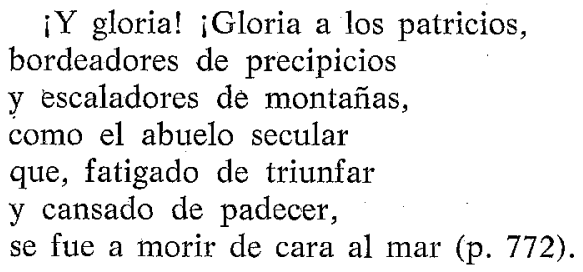

A veces, Darío parece apoyarse en obras anteriores. Por ejemplo, en los siguientes versos del Canto se nota la semejanza con algunos de la «Marcha triunfal», poesía esta última que había escrito en Buenos Aires en 1895:

iSonad, oh claros clarines, sonad, tambores guerreros, en el milagroso escenario; los nombres de los paladines (p. 775).

También en una de las estrofas más felices del poema de 1910 parece resurgir el ímpetu soberbio de la «Salutación del optimista», incluida en los Cantos de vida y esperanza, de 1905:

Te abriste como una granada, como una ubre te henchiste, como una espiga te erguiste a toda raza congojada (p. 760).

Aunque durante los cinco años de su residencia en la Argentina Darío debe haberse familiarizado con los hechos más importantes de la historia del país, nos parece probable que, puesto a redactar el Canto, se ayudara con la lectura de algunos textos. Estos pueden haberle ofrecido datos que, aunque secundarios, le resultaran más apropiados para versificarlos. Este sería el caso para la mención bastante extensa que dedica a Hipólito Bouchard, marino, quien entre 1817 y 1819 cumplió con la fragata $L a$ Argentina una extraordinaria campaña de corso contra los españoles, la que lo llevó desde Madagascar a las Filipinas, las antiguas Sandwich, y luego, por el Pacífico, desde California hasta Chile. Bouchard combatió bajo las órdenes de San Martín, pero no alcanza la fama del almirante Guillermo Brown, para los argentinos el máximo héroe naval de las luchas de independencia. Darío castellaniza el apellido del francés: 


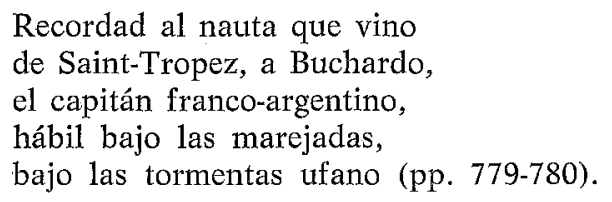

La considerable extensión del Canto a la Argentina permite incluir una cantidad de temas. Una enumeración escueta de los más importantes, de acuerdo al orden en que aparecen, resultaría lo siguiente: la Argentina como tierra de promisión, de libertad y paz (pp. 759-760, 767, 784785); los inmigrantes (pp. 761-764); la pampa y el gaucho (pp. 764-766, 779); Buenos Aires (pp. 767-769); el Río de la Plata (p. 769); el trabajo comercial e industrial (p. 770); Latinidad y Humanidad (p. 771); la raza hispánica (p. 772); San Martín y los héroes (pp. 772-773); el sol tutelar «desde 1a enseña argentina» (pp. 773-774); la mujer (pp. 776-778); la paz (pp. 780, 783, 784); las Américas y la hermandad continental y de razas (pp. 781-782); los reyes y dioses antiguos (p. 782); la Argentina como el país de la fraternidad y del futuro (pp. 784-786).

En el tratamiento poético de los mismos, Darío acierta las más de las veces. Así, cuando modifica el ritmo de la estrofa sobre la base de la variación en el ordenamiento de las líneas:

sobre el construir, sobre el bregar, sobre el soñar,

sobre la blanca sierra, sobre la extensa tierra, sobre la vasta mar (p. 759).

O cuando anota rasgos de belleza en la mujer argentina, en forma que recuerda el retrato de la bailarina española, en los Versos sencillos, de Martí:

Talle del vals es de Viena, ojo morisco es de España, crespa y espesa pestaña es de latina sirena (p. 777).

También se sirve de la aliteración:

te profetizan tus profetas

$y$ te poetizan tus poetas (p. 786).

$\mathrm{Y}$ a veces la combina con fuerte sinonimia (domingo $=$ fiesta):

Dad a todas las almas abrigo, sed nación de naciones hermana, convidad a la fiesta del trigo, al domingo del lino y la lana (p. 785). 
Los temas predominantes del Canto forman la imagen de la Argentina como tierra de paz y de prosperidad, que abre sus puertas al inmigrante, que procede de la estirpe latina e hispánica y que se levanta ya como la nación del porvenir. En uno de los ensayos que dedicó a la obra de Darío, dice Octavio Paz:

E1 Canto a la Argentina (1910) reúne sus ideas predilectas: paz, industria, cosmopolitismo, latinidad. El evangelio de la oligarquía hispanoamericana de fines de siglo, con su fe en el progreso y en las virtudes sobrehumanas de la inmigración europea ${ }^{42}$.

En la misma línea, Angel Rama sostiene que los versos del Canto a la Argentina pueden servir para ilustrar «una serie de rasgos típicos del fenómeno colonizador de los imperios», que en el período modernista en el Río de la Plata corresponden a «una acción económica que orienta Inglaterra» ${ }^{43}$.

Como veremos en seguida, estos juicios resultan igualmente pertinentes para aplicarlos al canto al Centenario de Lugones. Conviene, por tanto, pasar a la consideración de esta obra antes de hacer los comentarios a las opiniones críticas antes citadas.

\section{LEOPOLDO LUGONES Y LAS «ODAS SECULARES»}

Es a todas luces evidente que Lugones estaba en mejores condiciones que Darío para cantar a la Argentina del Centenario. Esto explicaría una estimación como la que anota Anderson Imbert: "Medido con las Odas, el Canto resulta tangencial y abstracto» ${ }^{44}$.

En primer lugar, el hecho de ser argentino le daba, desde el comienzo, la ventaja de una familiaridad con el país, su historia y sus gentes, familiaridad con la que no podía contar el nicaraguiense. En estrofa memorable, Lugones explica:

Así en profunda intimidad de infancia, El día de la patria en mi memoria, Vive a aquella dulzura incorporado Como el perfume a la hez de la redoma.

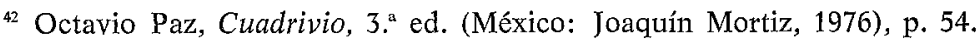

${ }^{43}$ Rama, p. 122.

${ }^{4}$ Anderson Imbert, p. 266. Para una comparación general de las dos obras, véase el breve estudio de Esther Carnicé de Gallez Lugones y Dario en el Centenario de Mayo (Bahía Blanca, Argentina: Universidad Nacional del Sur, 1962). 
iFeliz quien como yo ha bebido patria,

En la miel de su selva y de su roca! ${ }^{45}$

Otro factor importante es el lugar que el poema ocupa en relación con Ia obra total del autor. En el caso de Darío, el Canto a la Argentina es su canto del cisne. Por el contrario, en opinión de muchos críticos, las Odas seculares marcan el punto en que Lugones encuentra su voz más auténtica, tono que perdurará, acendrado, hasta los Romances del Río Seco, el libro póstumo, de 1938.

Si se observan los trabajos y la disposición del escritor en los años inmediatamente precedentes al del Centenario, ya vimos cómo, en 1909, Darío contestaba con desánimo y reticencia a la propuesta revolucionaria de Marinetti. En cambio, Lugones publica en 1909 el Lunario sentimental, con justicia reconocido como «un libro experimental, el más avanzado y atrevido hasta entonces en lengua española» ${ }^{46}$, libro que contiene, según Borges, «todo lo que se hizo después» ${ }^{47}$.

Lo que Lugones hace al año siguiente es escribir las Odas seculares, y no se puede concluir con certeza si la ocasión del Centenario fue el factor determinante que lo movió a centrarse en los temas argentinos, o si esta tendencia respondía a una evolución natural que se hubiera desarrollado aun sin la circunstancia de la celebración patriótica.

Las Odas seculares se inician con una invocación «A la Patria» (pp. 423-425), y se continúan en tres secciones dedicadas a «Las cosas útiles y magníficas» (pp. 426-468), a «Las ciudades» (pp. 469-475) y a «Los hombres» (pp. 476-480). Una simple ojeada a la paginación indica que las tres cuartas partes del libro corresponden a «Las cosas útiles y magníficas», sección que contiene tres odas: «Al Plata», "A los Andes» y «A los ganados y las mieses». Este último poema cubre casi toda la sección y, por lo tanto, casi todo el libro. Así, de entrada puede observarse que en su canto a la Argentina del Centenario Lugones pone el énfasis en la utilidad y magnificencia del trabajo agropectuario. Como Darío, también canta a Buenos Aires, a los gauchos y a los próceres. Pero todas esas composiciones resultan secundarias frente a la que se dedica «A los ganados y las mieses». En un ensayo que escribió con Betina Edelberg, Borges

${ }^{45}$ Leopoldo Lugones, Obras poéticas completas, 3. ${ }^{2}$ ed. (Madrid: Aguilar, 1959), p. 468. De aquí en adelante, las referencias a los poemas de Lugones se harán sólo por número de página, según esta edición.

${ }_{46}$ Alfredo A. Roggiano, "Qué y qué no del Lunario sentimental», en Revisía Iberoamericana, 94 (enero-marzo de 1976): 76.

${ }^{47}$ Jorge Luis Borges, «Leopoldo Lugones», en La Universidad, 87.1-4 (San Salvador, 1962): 98 . 
critica el intento y la forma de desarrollarlo: «El defecto del libro reside en lo que algunos han considerado su mayor mérito: la tenacidad prolija y enciclopédica que induce a Lugones a versificar todas las disciplinas de la agricultura y de la ganadería» ${ }^{48}$. En efecto, si se atiende a las variedades de los sembrados que aparecen en los versos habría que anotar una larga enumeración con la cebada, el trigo, el maíz, el lino, el maní, el algodón, la caña de azúcar, la vid, el fríjol, la avena, el centeno, el sorgo y el arroz. Para los ganados, la lista es igualmente extensa: caballos, yeguas, vacas, vaquillonas, novillos, carneros, ternero, buey, mula, asno, cerdo y, en línea descendente, avestruz, pavo, oca, gallineta, conejo, palomas y abejas. Cada uno de los nombres, acompañado de los elocuentes epítetos lugonianos, cuyo tono seguirá resonando en obras futuras, como El libro de los paisajes o los Poemas solariegos. Así desfilan las vaquillonas lucientes (p. 432), los carneros rugosos (p. 433), el asno mendicante (p. 464), la vaca fértil (p. 432), el bronco cerdo (p. 465), el surgente avestruz (p. 465); estas y otras, imágenes que se extienden en escenas preciosas: «la modesta gallineta que huye / Con paso de mucama perentoria, / Y remeda a la lima del herrero, / Atareada como él desde la aurora» (p. 465). O «el conejo pueril en cuyo hocico / Pulula la esquivez como una mosca» (p. 465).

Pero Lugones no se conforma con estos alardes de riqueza poéticopecuaria y pasa a exaltar los productos derivados con un «Cantemos las primicias de la lana» (p. 451), «Cantemos a la carne brava y fuerte» (p. 454), «Cantemos a la leche cuyo gusto / Sabe a beso infantil en nuestra boca» (p. 455). De aquí va a las figuras de los que cumplen las tareas de producción y de comercio. Concede una estrofa al lechero vasco:

¡Oh alegre vasco matinal!, que hacía Con su jamelgo hirsuto y con su boina La entrada del suburbio adormecido Bajo la aguda escarcha de la aurora (p. 455).

Recuerda al agrónomo ( Congratulemos a la dulce ciencia / Del pacífico agrónomo que explora / En el paciente surco los secretos / De las plantas amigas...» [p. 450]), y al veterinario ( Cumplamos con el buen veterinario / Cuya modesta medicina aploma / Los miembros aquejados por el duro / Esparaván, o por la llaga crónica» [p. 459]). También al capataz ( Detrás, pausadamente talonea / El capataz su zaina cadencio-

${ }^{48}$ Jorge Luis Borges y Betina Edelberg, Leopoldo Lugones, en Obras completas en colaboración (Buenos Aires: Emecé, 1979), p. 476. 
sa, / En el chifle de cuerno un resto de agua / Va gorgoteando sofocada y sorda» [p. 461]), y, significativamente, al mayordomo inglés:

Aunque es ese buen mozo inglés cerrado,

Asaz gallardamente se acriolla,

Lo cierto es que en su media lengua trajo

Artes y ciencias que el paisano ignora.

E1 transformó los bárbaros corrales,

Las torpes hierras, las feroces domas,

$\mathrm{Y}$ aseguró en las chacras invernizas

Que al pronto parecieron anacrónicas,

Forraje fresco a los costosos padres

Que entienden sus maneras y su idioma (p. 444).

A los «costosos padres», los toros de raza ingleses y escoceses, los presenta en líneas que podrían servir como magníficas notas al pie de las fotografías de los campeones en la Exposición Rural, de aparición profusa en las páginas de La Nación y de otros diarios y revistas:

Cantemos la excelencia de las razas

Que aquella sangre indígena mejora.

Con el marmóreo Durham de los premios,

Con el Hereford rústico que asocia

A la belleza de su manto rojo,

En blancura total cabeza y cola.

Con la negra nobleza que propala

El Polled-Angus de cabeza mocha (p. 457).

Todavía más potente en su eficacia verbal la descripción del toro Shorthorn, que figura en páginas anteriores:

Una sangre excelente engarza su ojo

Con bravío coral. Fuego de aurora

Parece que se atarda empurpurando

En su tostada piel. Su poderosa

Fábrica, funda en los enjutos remos

Una gravedad brusca y categórica.

$Y$ los vastos cuadriles y los flancos

Que así parece ponderar la norma

Del muro racional, y el rudo pecho

Que en la crasa marmella se desborda,

Acumulando en la cerviz su fuerza

Como en un tronco de coraje, aploman 
El macizo trapecio de la testa

Donde es padrón de raza el asta corta (p. 431).

Llevado por su afán inclusivo, a lo filósofo a quien nada le es ajeno, apoyado con suficiencia en el desborde de sus posibilidades expresivas y también con la intención de discutir ideas que eran parte de su visión social, Lugones se deriva a temas que, con frecuencia, lo hacen caer en un prosaísmo gratuito. Por ejemplo, cuando habla del código rural: «Reclamemos la enmienda pertinente / Del código rural cuya reforma, / En la nobleza del derecho agrícola / $\mathrm{Y}$ en la equidad pecuaria tiene normas» (p. 460). Lo mismo cuando se refiere al fraude electoral: «Si el mismo capataz no está seguro / Cuando, los días de elección, no vota / Como todo mensual por 'don Fulano' / La lista que al fin poco les importa» (p. 461). También trae la referencia a las reivindicaciones del trabajador: «Y ya la peonada regalona, / Habla de socialismo y hasta pide / La jornada de ocho horas...» (p. 435).

Bien integrada, en cambio, es la alusión a la Ley 1420, de Educación Común, obligatoria, grautita y laica. Esta ley, quizás el mayor legado de los hombres de la Generación del 80, propició una instrucción masiva y, en pocas décadas, puso a la Argentina entre los países con mejor índice de alfabetización. Un problema generalizado en las áreas rurales era el del ausentismo de muchos niños en edad escolar debido a que sus padres, o los dueños de los establecimientos donde trabajaban, los retenían atados a sus tareas. Por esto una disposición legal autorizaba el uso de la fuerza pública para llevar a los niños a la escuela. Lugones la dramatiza así: «Ahijado del patrón, todos extrañan / Que en la escuela del pueblo no lo pongan. / Dicen que hay una ley que así lo ordena, / Pero ¿quién ha de abrir por él la boca?» (p. 461).

De acuerdo con los intereses de la llamada «patria liberal» ${ }^{49}$, y en esto semejante a Darío, Lugones habla de los inmigrantes (pp. 435-438) $\mathrm{y}$ de los ferrocarriles (pp. 431-432). Bien preciso, anota datos sobre las exportaciones:

Ayer, en el diario, le han leído

Las cantidades que el país exporta.

Con nueve toneladas en un año,

Va a hacer cuarenta que iniciaron la obra.

Más de cuatro millones en un día,

Buenos Aires tan sólo embarca ahora (p. 434).

${ }^{49}$ Véase el apartado correspondiente en el artículo de Jaime Delgado "Cántico en centellas: La Argentina de Leopoldo Lugones», en Cuadernos hispanoamericanos, 224-225 (agosto-septiembre de 1968): 304-315. 
También observa las posibilidades del productor agropecuario para obtener un enriquecimiento rápido: « $\mathrm{Y}$ así fue como una cosecha pródiga / Aseguró el pasar de la familia, / Que ya en fortuna sus desvelos goza» (p. 437).

Lo curioso es que, según opinan sus biógrafos, por la época de la redacción de las Odas Lugones se inclinaba más a favorecer la posición de la burguesía industrial que la de la oligarquía terrateniente ${ }^{50}$. Estas incoherencias, aparentes o reales, en la ideología lugoniana han sido analizadas por los críticos y, en algunos casos, juzgadas con severidad. Noé Jitrik afirma: «Lugones no advirtió las constantes del país en que vivía, no comprendió el fenómeno del imperialismo y tampoco el papel que la Argentina jugaba en el mundo» ${ }^{51}$. Ciertamente, resulta difícil explicar el giro de ciento ochenta grados que media entre su juvenil anarquismo socialista y la postura totalitaria y elitista del discurso de 1924 en Ayacucho, cuando sostiene: «El ejército es la última aristocracia, vale decir, la última posibilidad que nos resta entre la disolución demagógica» ${ }^{52}$. En lo que sí es constante es en la firme convicción con que defiende sus ideas, lo que lo convertía en formidable polemista.

Aunque relacionados con el tema central de nuestro estudio, estos cambios en la posición ideológica del escritor resultan poco significativos en cuanto a las conclusiones hacia las que nos dirigimos, al punto de que para seguir la marcha podemos aceptar sin inconvenientes una de las opiniones de Borges sobre Lugones: «Sus razones casi nunca tenían razón; sus epítetos, casi siempre» ${ }^{53}$.

En las Odas seculares, el acierto de los epítetos y de los otros recursos poéticos es evidente. En especial, cuando el autor se da a una aproximación más espontánea e inmediata de los seres y de las cosas. Así, al Río de la Plata no sólo lo ve como al después tan repetido «río color de león» (p. 469), sino que lo reconoce «Moreno como un Inca» (p. 427), y lo exalta así:

Corazón de la patria que palpitas

Heroicamente en ella, a flor de pecho, Como si desbordaras en la noble

Quimera de endulzar el mar entero (p. 427).

\footnotetext{
${ }^{50}$ Canedo, p. 101.

${ }^{51}$ Noé Jitrik, Leopoldo Lugones, mito nacional (Buenos Aires: Palestra, 1960), p. 24 .

52. Párrafo citado en el estudio de Julio Irazusta Genio y figura de Leopoldo Lugones (Buenos Aires: Editorial Universitaria de Buenos Aires, 1968), p. 107.

${ }^{53}$ Borges-Edelberg, p. 500.
} 
Canta en otros versos las excelencias del trigo:

En la fiel solidez del pan seguro, La vida es bella y la amistad sonora.

Suave corre la vida en las cordiales

Tierras del pan, como una lenta sombra (p. 434).

Recuerda con orgullo su origen serrano: «Yo, que soy montañés, sé lo que vale / La amistad de la piedra para el alma» (p. 430).

Y culmina el tono íntimo, cuando en el canto al país incluye la imagen de su madre:

Aunque aquí vaya junto con la patria

Toda luz, es seguro que no estorba,

Adelgazada por penosos años,

Como el cristal casi no tiene sombra (p. 466).

En la lírica hispanoamericana, sólo los versos que Vallejo dedicó a su madre en «Los pasos lejanos» pueden equipararse a éstos en la fuerza y delicadeza del sentimiento filial:

Y mi madre pasea allá en los huertos, saboreando un sabor ya sin sabor.

Está ahora tan suave, tan ala, tan salida, tan amor ${ }^{54}$.

Ya al final de este estudio, conviene repetir aquí algunas de las propuestas iniciales sobre las que organizamos su estructura. Desde el título se indicó la intención de analizar el Canto a la Argentina de Rubén Darío y las Odas seculares de Leopoldo Lugones en su relación con las circunstancias histórico-sociales y en su calidad de obras modernistas.

Uno de los temas centrales a dilucidar era el de la originalidad y autonomía de estas creaciones poéticas. Françoise Perus sostiene que las obras que perduran son aquellas «que mejor han logrado plasmar las posibilidades que cada fase histórica ofrece a la producción literaria». Según esto, lo que el escritor hace es elaborar «esas posibilidades históricamente determinadas» ${ }^{55}$. La crítica tradicional, como la que formula José Enrique Rodó con ocasión de la muerte de Darío, también reconoce la «adecuación de la índole de las propias facultades a la oportunidad del tiempo

${ }^{54}$ César Vallejo, Los heraldos negros, 2. ${ }^{\mathrm{a}}$ ed. (Buenos Aires: Losada, 1966), p. 101.

${ }^{55}$ Perus, p. 8. 
y del lugar en que ellas han de revelarse» ${ }^{56}$. Pero Rodó ve esta relación en sentido positivo, como el resultado de situaciones favorables que, en el caso de ciertos escritores como Darío, permiten que se alcance «la armonía dichosa entre el momento en que se llega y el género de obra de que se es capaz» ${ }^{57}$. Perus, en cambio, presenta una interpretación bastante rígida, según la cual, en el ejercicio de su labor creadora, el artista depende casi por completo de las circunstancias del lugar y de la época en las que está ubicado. Si como, en el caso del modernismo hispanoamericano, el período histórico que abarca es calificado en forma negativa desde el punto de vista ideológico — «implantación del modo de producción capitalista en escala continental»—, esa devaluación se traslada, de alguna manera, al juicio estético de las obras y de los escritores. Una de las objeciones que Perus hace a las opiniones de Rama — a quien, en general, alaba por el valor de su ensayo sobre Dario- se refiere precisamente al tema de la autonomía poética. Si bien el crítico uruguayo reconoce las mismas evidencias de dependencia económica y cultural de Hispanoamérica en relación con las potencias hegemónicas, también considera que la forma en que los modernistas utilizaron las posibilidades de renovación que el sistema les permitía constituye, según sus palabras, «el más ingente esfuerzo creativo de la poesía hispanoamericana, al incorporarse al mercado único cultural y económico que establece la burguesía europea y norteamericana al iniciar la conquista y unificación del mundo entero» ${ }^{58}$. Para darse una idea de la magnitud y dificultades de esta empresa basta leer algunos párrafos del artículo que Paul Groussac publicó a principios de 1897, a propósito de Prosas profanas ${ }^{59}$. El erudito francés, radicado en la Argentina, explica con bastante arrogancia por qué se resigna «a envejecer lejos del foco de toda civilización, en estas tierras nuevas, por ahora condenadas a reflejarla con más o menos fidelidad». Y, rotundamente, afirma: «Es, pues, necesario partir del postulado que, así en el norte como en el sur, durante un período todavía indefinido, cuanto se intente en el dominio del arte es y será imitación.» Groussac justifica, en parte, la adhesión de Darío al decadentismo francés «por desdén explicable de la actual indigencia española». Pero al mismo tiempo sigue firme en el juicio definitivo: «la América colonizada no debe pretender por ahora a la originalidad intelectual». Esta es la realidad y el dilema que enfrentan los modernistas en cuanto a la autonomía de la creación literaria: separarse de lo español, que en el presente les resulta precario e insuficiente, y unirse

\footnotetext{
56 José Enrique Rodó, «Rubén Darío», en Nosotros, 10.21 (1916): 127.

57 Rodó, p. 127.

${ }^{58}$ Rama, p. 124.

${ }^{59}$ Paul Groussac, «Prosas profanas», en Nosotros, 10.21 (1916): 157-160.
} 
a las corrientes que vienen de las potencias europeas -Francia es especial-, las que sólo los reconocerán en una relación de dependencia cultural. Los azares de este intento marcan altos y bajos en la vida y en la abra de los escritores modernistas, pero, en general, no cabe ninguna duda acerca del valor de tal propósito.

El modernismo será también fructífero en cuanto a la unión de los escritores en el reconocimiento de su identidad hispanoamericana. Darío lo observa en las patrias de la América Central:

Dios eterno y único haga que lo que es un hecho en Literatura (la unidad) pueda realizarse para Centro-América en Política, por ley histórica y por necesidad de nuestra civilización ${ }^{60}$.

Sabemos que estos buenos deseos del nicaragüense no se cumplieron en ninguna región de Hispanoamérica. En cambio, en el terreno de la expresión poética los modernistas alcanzaron la meta de unidad continental. Los versos de Martí, Gutiérrez Nájera, Silva, Darío, Lugones, Herrera y Reissig, Jaimes Freyre y otros se repiten en distintos lugares y países sin importar y, generalmente, sin recordar si se trata de un escritor cubano, mexicano, colombiano, nicaragüense, argentino, uruguayo o boliviano.

Aun en el plano de la difusión popular y masiva se dan ejemplos elocuentes y curiosos. Así, cuando multitudes entusiastas escuchan uno de los tangos más famosos de Gardel, pocos saben - y no tienen por qué saberlo- que el autor de la letra estaba casi glosando versos de un poema del modernista Amado Nervo: «El día que me quieras tendrá más luz que junio; / la noche que me quieras será de plenilunio» ${ }^{61}$.

Es que la renovación modernista se apoyó por sobre todo en el lenguaje, y con éste y a través de éste obró con más intensidad y efecto que otras acciones en apariencia más significativas.

En tono mesurado, sin vanas grandilocuencias, Lugones había anotado:

... hallar imágenes nuevas y hermosas, expresándolas con claridad y concisión, es enriquecer el idioma, renovándolo a la vez. Los encargados de esta obra, tan honorable, por lo menos, como la de refinar los ganados o administrar la renta pública, puesto que se trata de una función social, son los poetas. El idioma es un bien social, y hasta el elemento más sólido de las nacionalidades (p. 192).

${ }^{60}$ Citado en el libro de Contreras, p. 126.

${ }^{61}$ Amado Nervo, «El día que me quieras», de El arquero divino, en Obras completas, II (Madrid: Aguilar, 1952), p. 1799. Véanse, para este tema, los comentarios de Ernesto Sábato en Tango: Discusión y clave, 3. ${ }^{a}$ ed. (Buenos Aires: Losada, 1968), pp. 138-141. 
